\title{
A COMPARATIVE STUDY OF WHOLE-BODY VIBRATION EXPOSURE IN TRAIN AND CAR PASSENGERS: A CASE STUDY IN MALAYSIA
}

\author{
M.Z. Nuawi ${ }^{1}$, A.R. Ismail ${ }^{2}$, M.J.M. Nor ${ }^{1}$ and M.M. Rahman ${ }^{2}$ \\ ${ }^{1}$ Department of Mechanical and Materials Engineering, \\ Faculty of Engineering and Built Environment, University Kebangsaan Malaysia, \\ 43600 UKM Bangi, Malaysia; \\ Phone: +603-89216775, Fax: +603-89259659 \\ E-mail: fanakamaruddin@gmail.com \\ ${ }^{2}$ Faculty of Mechanical Engineering, Universiti Malaysia Pahang, \\ 26600 UMP, Pekan, Pahang, Malaysia; \\ Phone: +6012-3456789, Fax: +609-87654321 \\ E-mail: arasdan@gmail.com
}

\begin{abstract}
Trains and cars are the most important modes of transportation throughout the world. In highly developed countries, trains have become essential for human use as the most well-known form of public transportation, whereas the car plays a significant role in prompt human travel from one place to another. The high magnitude of vibration caused by trains and cars may cause health problems in humans, especially low back pain. The aim of this study was to evaluate and validate the values of daily exposure to vibration $\mathrm{A}(8)$ and the vibration dose value (VDV) in passengers travelling by train and car and to assess the effects produced by this exposure on the human body. Moreover, this study introduces a newly developed whole-body vibration measurement instrumentation system. One train travelling from the east coast to the south of Malaysia was chosen to conduct the study. Whole-body vibration exposure was measured over 8 hours, which is equal to the duration of normal occupational exposure. One car was chosen randomly and whole-body vibration exposure was measured for $5 \mathrm{~min}$ and $10 \mathrm{~min}$. All the data were computed using an $\mathrm{IEPE}\left(\mathrm{ICP}^{\mathrm{TM}}\right)$ accelerometer sensor connected to a DT9837 device which is capable of effectively measuring and analysing vibration. The vibration results were displayed on a personal computer using a custom graphical user interface (GUI). Matlab software was used to interpret the data. From the results, the whole-body vibration exposure level could be determined. It can be concluded that the whole-body vibration absorbed by the human body is enhanced when the magnitude of the vibration exposure experienced by the passengers increased. This was shown by the increased values of daily exposure to vibration $\mathrm{A}(8)$ and VDV calculated in the study.
\end{abstract}

Keywords: Whole-body vibration; daily exposure to vibration $\mathrm{A}(8)$; vibration dose value; low back pain; vibration.

\section{INTRODUCTION}

Ergonomics is the application of scientific principles, methods and data drawn from a variety of disciplines to the development of engineering systems in which people play a significant role. Among the basic disciplines are psychology, cognitive sciences, physiology, biomechanics, applied physical anthropometry and industrial systems engineering (Kroemer et al., 2003). Matilla (1996) mentioned that the importance of 
safety and ergonomics has grown significantly. The latest technology has increased the option of broadening ergonomics and the safety features of products and equipment. However, it will also create new risks and the way to manage it would become more complicated. Therefore, it is important for the designer to use ergonomic knowledge in making decisions during of machines, equipment, products and systems. There is substantial epidemiologic evidence of associations between physical exposure at the workplace, such as lifting, constrained postures, repetitive movements, a fast work pace, heavy material manual handling, forceful exertions and vibration, and the occurrence of upper extremity musculoskeletal disorders (Bernard, 1997; Grieco et al., 1998; Hagberg et al., 1995; NRCIM, 2001; van der Windt et al., 2000). To be more specific, ergonomics (also called human factors or human engineering in the United States) is defined as the study of human characteristics for the appropriate design of the living and working environment. Its fundamental aim is that all human-made tools, devices, equipment, machines and environments should advance, directly or indirectly, the safety, well-being and performance of human beings (Kroemer et al., 2003). Several ergonomic interventions, such as employee training, redesign of process tools or workstations and improvement of working conditions, have been suggested to reduce musculoskeletal problems in industry (Wang et al., 2003; Weestgard and Winkel, 1997).

Various definitions have been given to whole-body vibration (WBV) by dictionaries, companies and researchers themselves. From the Directive 2002/44/EC of the European Parliament and of the Council, the term "whole-body vibration" means the mechanical vibration that, when transmitted to the whole body, entails risks to the health and safety of workers, in particular lower-back morbidity and trauma of the spine (Directive 2002/44/EC). WBV is defined as vibration occurring when a greater part of the body weight is supported on a vibrating surface. WBV principally occurs in vehicles and wheeled working machines. In most cases, exposure to WBV occurs in a sitting position and the vibration is then primarily transmitted through the seat pan, but also through the back rest. WBV may impair performance and comfort. It has also been claimed to contribute to the development of various injuries and disorders. In many work situations, WBV is therefore an evident and annoying occupational health problem (Griffin et al., 1990).

Low back pain (LBP) is among the most common and costly health problems (Garg and Moore, 1992; van Tulder et al., 1995). Occupational, non-occupational and individual risk factors play a role in the development, duration and recurrence of LBP. Several critical reviews have discussed the evidence on occupational risk factors for back disorders (Burdorf and Sorock, 1997; Bovenzi and Hulshof, 1999; Lings and Leboeuf-Yde, 2000; Waddell and Burton, 2000). All these reviews conclude that there is strong epidemiological evidence for a relationship between occupational exposure to WBV and LBP. In five European countries (Belgium, Germany, Netherlands, France and Denmark), LBP and spinal disorders due to WBV are currently recognised as an occupational disease (Hulshof et al., 2002). However, high exposures and adverse effects still occur as WBV is a common occupational risk factor for LBP, affecting 4\% to $8 \%$ of the workforce in industrialised countries (Palmer et al., 2000). Important high risk groups are drivers of off-road vehicles (for example, earth moving, forestry and agricultural machines), drivers of forklift trucks, lorries or buses, crane operators and helicopter pilots. 


\section{EXPERIMENTAL DESIGN}

Whole-body vibration measurements were performed according to ISO 2631-1:1997. The triaxial accelerometer sensor was located between the train and car's passenger contact points with the vibration source. Then, the passenger sat on the accelerometer, as shown in Figure 1.

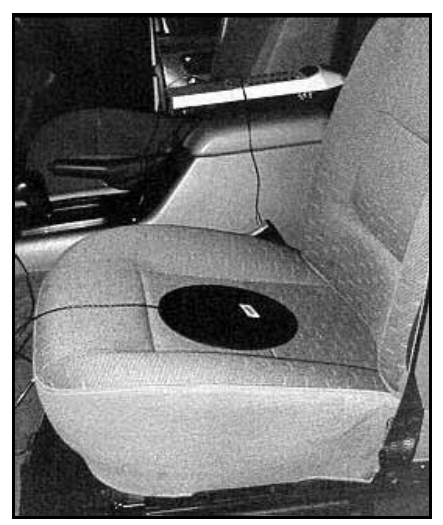

Figure 1. Triaxial accelerometer sensor used for WBV measurements

Two devices were used in the study, including the $\mathrm{IEPE}\left(\mathrm{ICP}^{\mathrm{TM}}\right)$ accelerometer sensor and the DT9837 instrument. As seen in Figure 2, the IEPE $\left(\mathrm{ICP}^{\mathrm{TM}}\right)$ accelerometer sensor (also known as a triaxial seat accelerometer) used in this study was DYTRAN Model 5313A. The sensor was utilised to assess the vibration level. The accelerometer consists of a piezoelectric element connected to a known mass. When the accelerometer is vibrated, the mass applies force to the piezoelectric element, generating an electrical charge that is proportional to the applied force. Then, this charge was measured to determine the vibration characteristics. Most accelerometers require a current source of $4 \mathrm{~mA}$ and a compliance voltage of at least $18 \mathrm{~V}$ to drive their internal circuitry. Other accelerometers require a $2 \mathrm{~mA}$ current source, but have limitations in cable length and bandwidth. The DT9837 instrument is a highly accurate five channel data acquisition module that is ideal for portable noise and vibration measurements. It has four simultaneous, 24-bit A/D channels for high resolution measurements. This instrument supports for four IEPE inputs, including the $4 \mathrm{~mA}$ current sources. Portable operation is possible with the DT9837 because no external power supply is needed and it runs on USB power. The DT9837 has a tachometer input support in the A/D data stream for synchronising measurements. This instrument has a sampling rate of over $52 \mathrm{kHz}$. It has low frequency measurements supported with a wide pass band of $0.5 \mathrm{~Hz}$ to $25.8 \mathrm{KHz}$ (0.49 x sampling frequency). The DT9837 is a programmable trigger with analogue input operations for maximum flexibility. Figures 3 and 4 show the DT9837 model and summarise the features of the instrument.

In this study, Matlab software was applied to analyse the vibration signal gathered by the DT9837 instrument from the USB port. The Matlab GUI scripts were examined by using the GUIDE function for ease of measurement and the assessment of WBV exposure. From this Matlab script, three graphs of each axis were measured for the analysis. Additionally, the data and vibration signal can be saved in the personal computer for subsequent analysis. Thus, the total of daily exposure to vibration for a human can be evaluated through the accelerometer sensor, the DT9837 instrument and the Matlab software. 


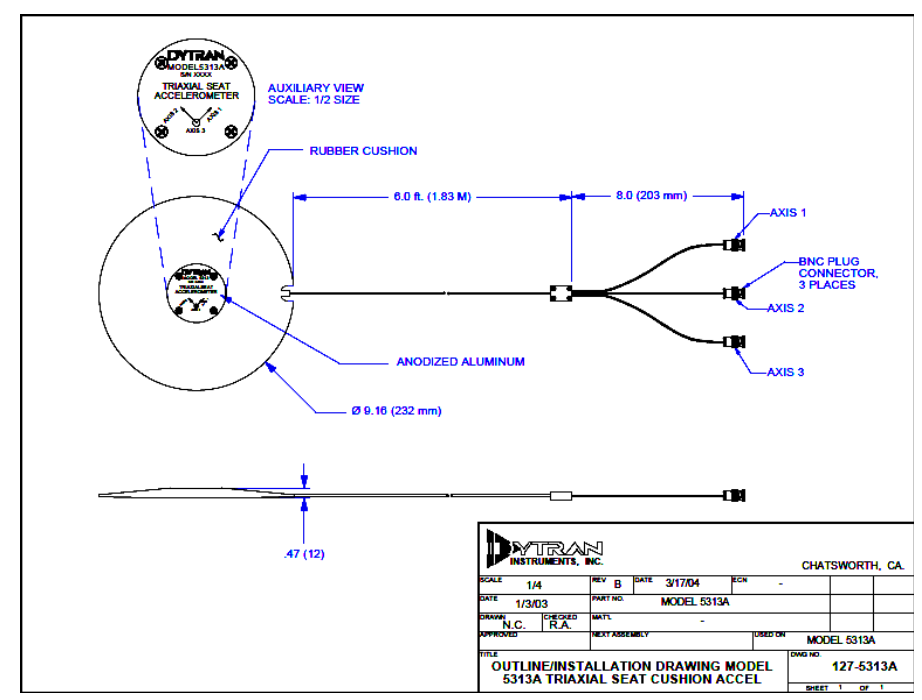

Figure 2. Triaxial seat accelerometer (DYTRAN model 5313A)

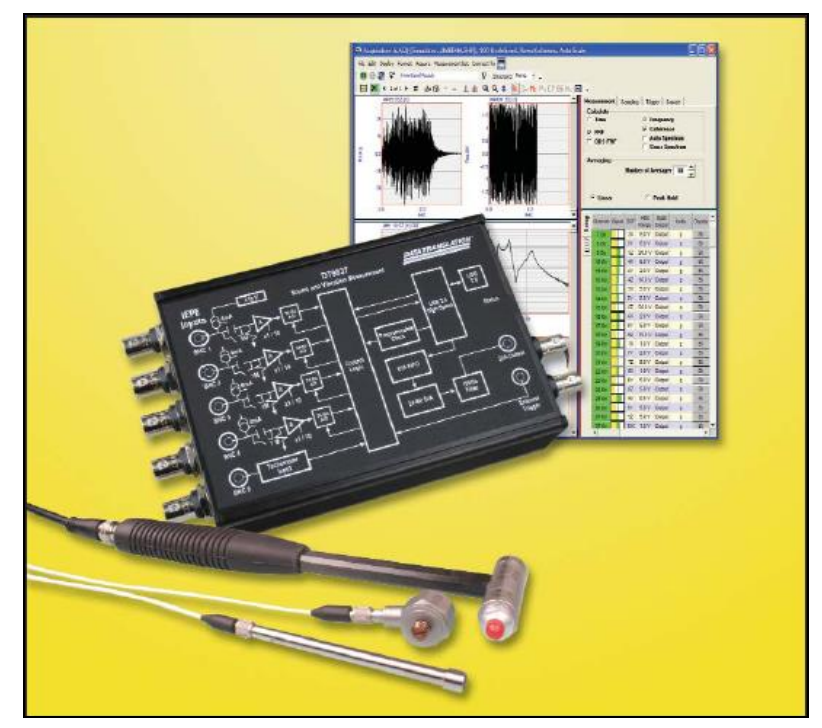

Figure 3. DT9837 device

\begin{tabular}{|c|c|c|c|c|}
\hline \multicolumn{5}{|c|}{ Summary of Features } \\
\hline $\begin{array}{c}\text { A/D } \\
\text { Throughput } \\
\text { per Channel }\end{array}$ & $\begin{array}{c}D / A \\
\text { Channels }\end{array}$ & $\begin{array}{c}\text { Tachometer } \\
\text { Input }\end{array}$ & $\begin{array}{c}\text { Simultaneous } \\
\text { Subsystem } \\
\text { Operation }\end{array}$ & Applications \\
\hline $\begin{array}{c}52.734 k \mathrm{k} z \\
\text { 4IEPE Inputs } \\
\text { Simultaneous }\end{array}$ & $\begin{array}{c}\text { 1Waveform } \\
\text { or Single } \\
\text { Value }\end{array}$ & $\begin{array}{c}\text { 1 Synchronous } \\
\text { to Analog Data } \\
\text { Stream }\end{array}$ & Yes & $\begin{array}{c}\text { Vibration, } \\
\text { Acoustics, } \\
\text { Sonar }\end{array}$ \\
\hline
\end{tabular}

Figure 4. Summary features of the DT9837 device

Matlab is a well-known interactive software environment for data acquisition and analysis, report generation, and test system development. It provides a complete set of tools for acquiring and analysing analogue and digital input output signals from a variety of PC-compatible data acquisition hardware. The Matlab Data Acquisition 
Toolbox configured the external hardware devices, read data into Matlab and Simulink for immediate analysis and sent out data for controlling the system. The diagram shown in Figure 5 depicts an example using Matlab and the Matlab Data Acquisition Toolbox with Data Translation's DT9837 device to acquire vibration data from the USB modules. Notice that the Data Translation device provides an interface layer, called the DAQ adaptor for Matlab, which allows the Matlab Data Acquisition Toolbox to communicate with the hardware of the Data Translation instrument. While the Data Acquisition Toolbox is collecting data, Matlab can analyse and visualise the data.

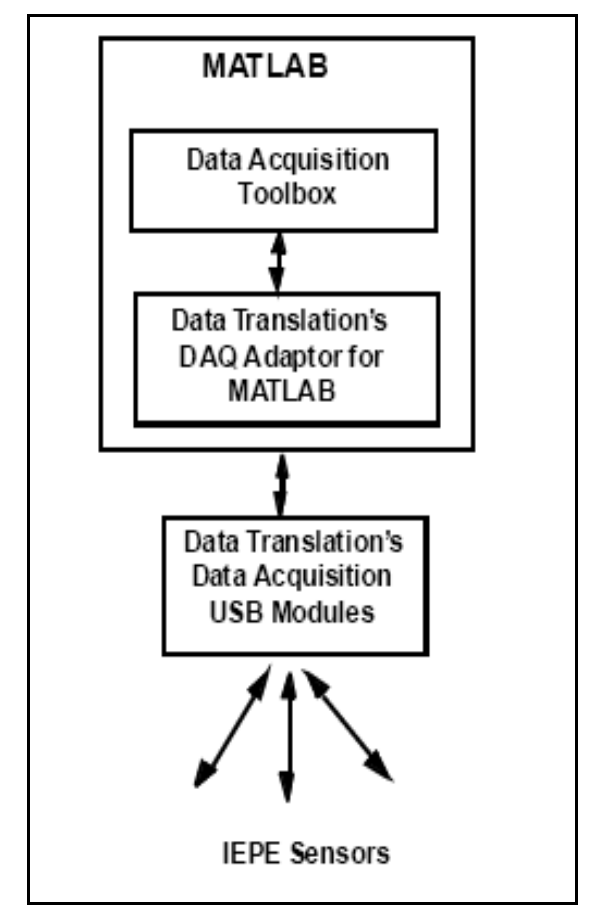

Figure 5. Flow chart of the data acquisition process

Excessive exposure to whole-body vibration usually occurs at the workplace and often involves a long duration of exposure and a high magnitude of vibration. Trains produce the highest magnitude of vibration of the various forms of public transportation, and road surface conditions are an environmental factor that may contribute to high magnitude vibrations. In this study, the assessment of whole-body vibration was performed by defining a sampling rate of 1000 samples per second. Compution of the exposure time was set to 8 hours for each experiment, which is equal to the duration of normal occupational exposure. After the accelerometer and the DT9837 instrument were connected, the process of data acquisition of the train vibration was started. The total vibration of each axis (the $\mathrm{x}, \mathrm{y}$ and $\mathrm{z}$-axes) felt by the passenger was displayed in a plotted graph using Matlab software. A train travelling from the east coast to the south of Malaysia was chosen for this study. The study was conducted at different locations. The location of measurement for each experiment is described in Table 1. Whole-body vibration measurements on the passenger were assessed three times at different locations, i.e. from Kajang to Seremban, from Seremban to Gemas and from Segamat to Tampin. 
Table 1. Location of measurements

\begin{tabular}{cc}
\hline Experiment & Location \\
\hline 1 & From Kajang to Seremban \\
2 & From Seremban to Gemas \\
3 & From Segamat to Tampin \\
\hline
\end{tabular}

Road surface conditions are an important parameter in assessing whole-body vibration exposure, especially at low frequencies. One car was selected for this study. The car passenger was picked up randomly without considering the individual characteristics of the passenger. In this study, the whole-body vibration measurement was done by varying the road conditions. The exposure time was set to $5 \mathrm{~min}$ and 10 min. The study was conducted at different locations with different road conditions, as described in Table 2. The measurement of whole-body vibration experienced by the car passenger was done three times under three different road conditions. The road conditions included an uneven and curved road, an even and curved road and finally an even and straight road.

Table 2. Road conditions

\begin{tabular}{ccc}
\hline Experiment & Measurement Time (min) & Road Condition \\
\hline 1 & 5 & Uneven and curved road \\
2 & 10 & Even and curved road \\
3 & 10 & Even and straight road \\
\hline
\end{tabular}

\section{RESULTS AND DISCUSSION}

From these experiments, the daily exposure to vibration $\mathrm{A}(8)$ value, the VDV and the exposure point value were evaluated using formulas (1), (2) and (3). However, by using the Matlab GUI, the calculation of these values was done by choosing the analysis method from the Matlab menu. Hence, the results were displayed in the custom-made GUI.

Daily exposure to vibration $\mathrm{A}(8)$ is expressed as Eq. (1).

$$
A(8)=\text { Vibration value }\left(\frac{\mathrm{m}}{\mathrm{s}^{2}}\right) \times \sqrt{\frac{\text { Exposure time }(\mathrm{min})}{480(\min )}}
$$

The vibration dose value (VDV) is expressed as Eq. (2).

$$
V D V=\left(\int_{0}^{\mathrm{T}} a^{4}(t) d t\right)^{0.25}
$$

where $a(t)=$ frequency-weighted acceleration $\left(\mathrm{m} / \mathrm{s}^{2}\right)$ and $T=$ the total period of time during which the vibration occurs.

The exposure point value can be expressed as Eq. (3). 


$$
\text { Exposure points }=2 \times(\text { Vibration value })^{2}
$$

All the data obtained from the train are organised in Table 3. Whole-body vibration graphs are shown in Figure 6. In Figure 6(a), the graph of whole-body vibration was collected from Kajang to Seremban, while Figure 6(b) was from Seremban to Gemas and Figure 6(c) was from Segamat to Tampin. Figure 7 shows the calculation of the vibration dose value.

Table 3. Whole-body vibration measurement data collected on the train

\begin{tabular}{|c|c|c|c|}
\hline \multirow[t]{2}{*}{ Analysis Method } & Experiment 1 & Experiment 2 & Experiment 3 \\
\hline & $\begin{array}{cc}\text { From } & \text { To } \\
\text { Kajang } & \text { Seremban }\end{array}$ & $\begin{array}{cc}\text { From } & \text { To } \\
\text { Seremban } & \text { Gemas }\end{array}$ & $\begin{array}{cc}\text { From } & \text { To } \\
\text { Segamat } & \text { Tampin }\end{array}$ \\
\hline $\begin{array}{l}\text { Daily exposure to } \\
\text { vibration } \mathrm{A}(8)\end{array}$ & $0.3221 \mathrm{~m} / \mathrm{s}^{2}$ & $0.2884 \mathrm{~m} / \mathrm{s}^{2}$ & $0.3749 \mathrm{~m} / \mathrm{s}^{2}$ \\
\hline Exposure points system & 41.4867 points & 33.2716 points & 56.206 points \\
\hline $\begin{array}{l}\text { Vibration dose value } \\
\text { (VDV) }\end{array}$ & $1.1014 \mathrm{~m} / \mathrm{s}^{1.75}$ & $1.0973 \mathrm{~m} / \mathrm{s}^{1.75}$ & $1.2513 \mathrm{~m} / \mathrm{s}^{1.75}$ \\
\hline $\begin{array}{l}\text { Daily exposure action } \\
\text { value time }\left(0.5 \mathrm{~m} / \mathrm{s}^{2}\right)\end{array}$ & 9 hours 50 min & 12 hours $16 \mathrm{~min}$ & 7 hours $16 \mathrm{~min}$ \\
\hline $\begin{array}{l}\text { Daily exposure limit } \\
\text { value time }\left(1.15 \mathrm{~m} / \mathrm{s}^{2}\right)\end{array}$ & 52 hour $3 \mathrm{~min}$ & 64 hour 54 min & 38 hour $25 \mathrm{~min}$ \\
\hline Points per hour & 5.1858 points & 4.159 points & 7.0258 points \\
\hline $\begin{array}{l}\text { Time achieving } \\
1.75 \mathrm{~m} / \mathrm{s}^{1.75}\end{array}$ & 1 hour $29 \mathrm{~min}$ & 1 hour $30 \mathrm{~min}$ & $53 \mathrm{~min}$ \\
\hline
\end{tabular}

The results of this study indicate that, in experiment 3 , the values of daily exposure to vibration $\mathrm{A}(8)$ and VDV were much higher than in the other two experiments. The values of daily exposure to vibration A(8) and VDV were $0.3749 \mathrm{~m} / \mathrm{s}^{2}$ and $1.2513 \mathrm{~m} / \mathrm{s}^{1.75}$, respectively. It seems possible that these results were due to the rough track used by the train, the train operation style and speed differences compared to experiments 1 and 2 . In addition, the daily exposure action value time only required 7 hours $16 \mathrm{~min}$ to meet the standardised value of $0.5 \mathrm{~m} / \mathrm{s}^{2}$ for an eight hour reference period. Surprisingly, this result was found to exceed the standard time of whole-body vibration assessment, which is 8 hours, as stated in ISO 2631-1:1997. The reason for this is not clear, but it may have something to do with the speed of the train that generated the high magnitude of vibration. The high magnitude of whole-body vibration exposure produced by the train may contribute to musculoskeletal disorders in passengers. In reviewing the literature, a relationship was found between occupational vehicles and whole-body vibration exposure leading to musculoskeletal disorders.

In the car study, three different road surface conditions were used to assess whole-body vibration in a car. The first road type was the uneven and curved road at Golf Kajang. The second condition was an even and curved road at Universiti Kebangsaan Malaysia (UKM). The third road was an even and straight road at Bandar Baru Bangi. The speed of the car during the study was set to $40 \mathrm{~km} / \mathrm{h}$. All the data obtained in the experiment are organised in Table 4. Whole-body vibration graphs are shown in Figure 8. In Figure 8(a), the graph of whole-body vibration was collected on the uneven and curved road, while Figure 8(b) was from the even and curved road and Figure 8(c) was from the even and straight road. 


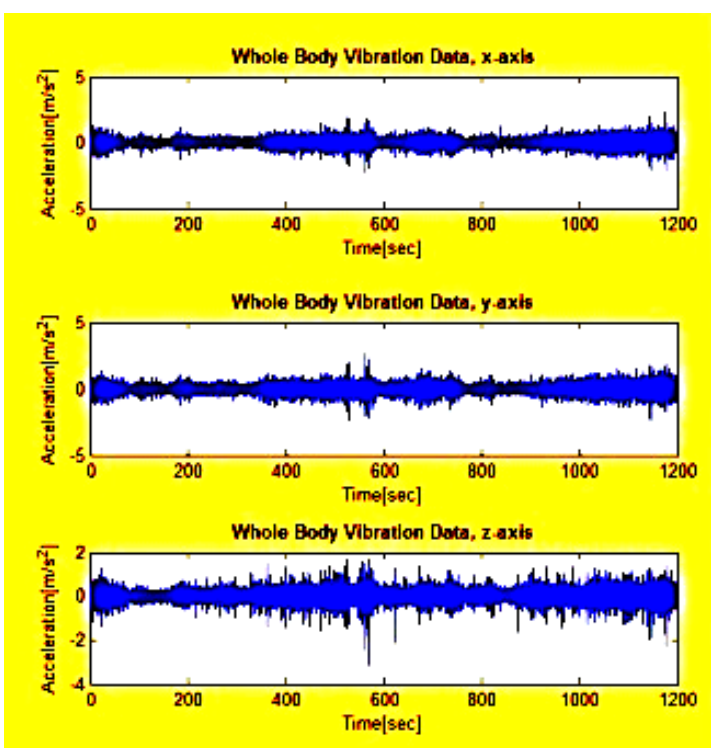

(a)
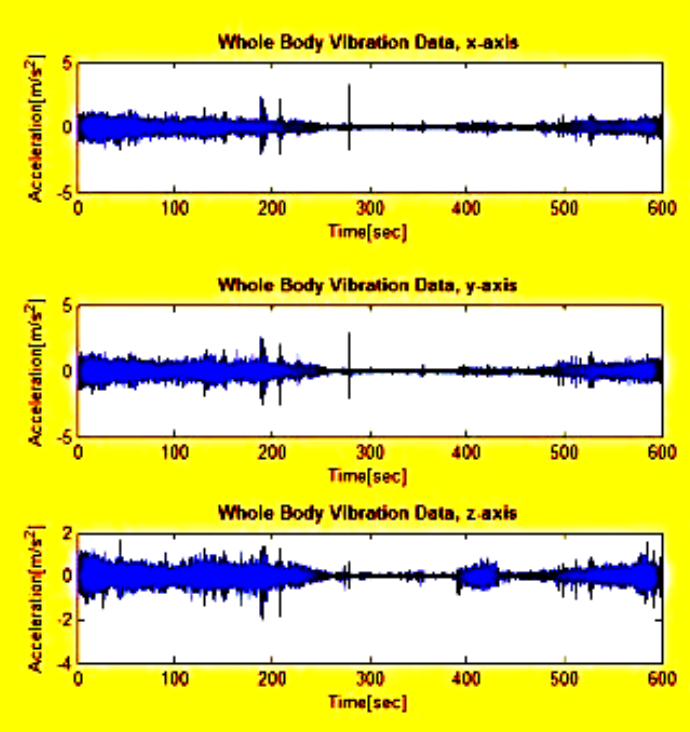

(b)
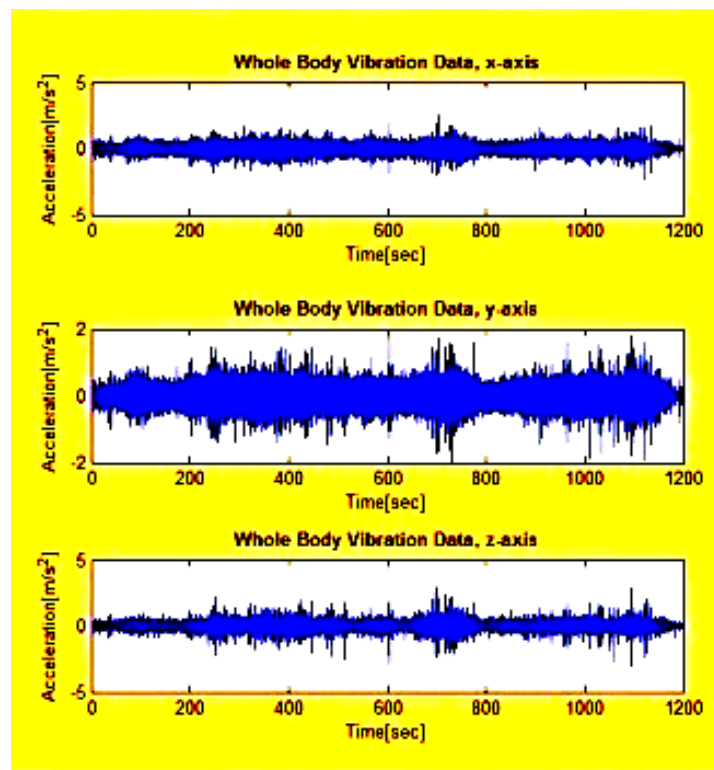

(c)

Figure 6. Whole-body vibration assessed by thecustom data acquisition system (a) from Kajang to Seremban, (b) from Seremban to Gemas, and (c) from Segamat to Tampin

The impact of whole-body vibration on human health is enhanced when the amplitude of the vibration signal absorbed by the human body is increased. This situation was shown by the comparison of the three experiments done in the present study. In the first experiment, the uneven and curved road surface had an increased vibration amplitude. Thus, the daily exposure to vibration A(8) and the VDV absorbed by the passenger were higher compared to experiment 2 and experiment 3 , even though the measurement time was only $5 \mathrm{~min}$. At the same time, the exposure whole-body vibration points system value in experiment 1 was high. In other words, the daily exposure action value time $\left(0.5 \mathrm{~m} / \mathrm{s}^{2}\right)$ and the daily exposure limit value time $(1.15$ $\mathrm{m} / \mathrm{s}^{2}$ ) were lower than in experiments 2 and 3 . From these results, the frequency 
weighted acceleration value indicated in this study was close to the permissible value of the exposure limit stated according to ISO 2631-1:1997. Therefore, this high magnitude of WBV may cause musculoskeletal disorders to train and car passengers.

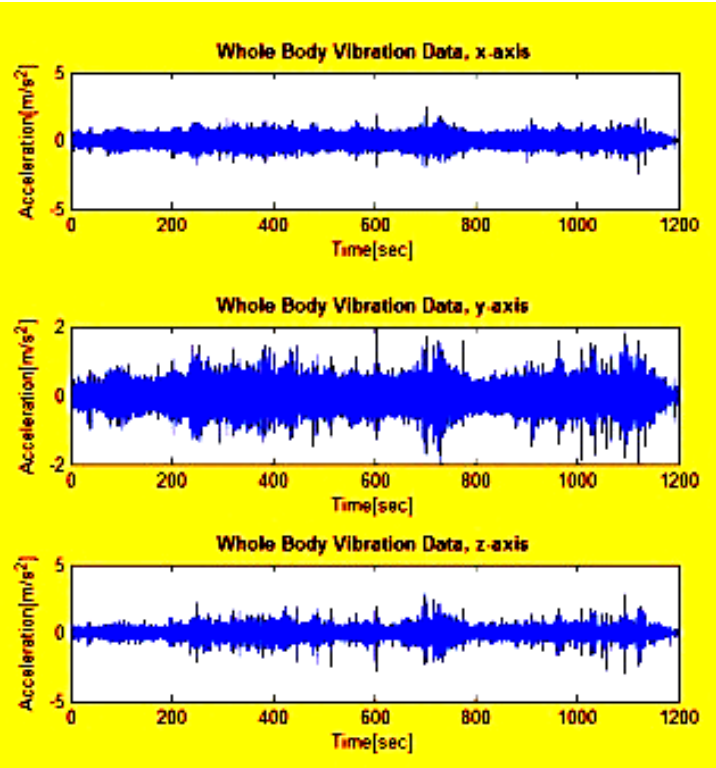

(a)
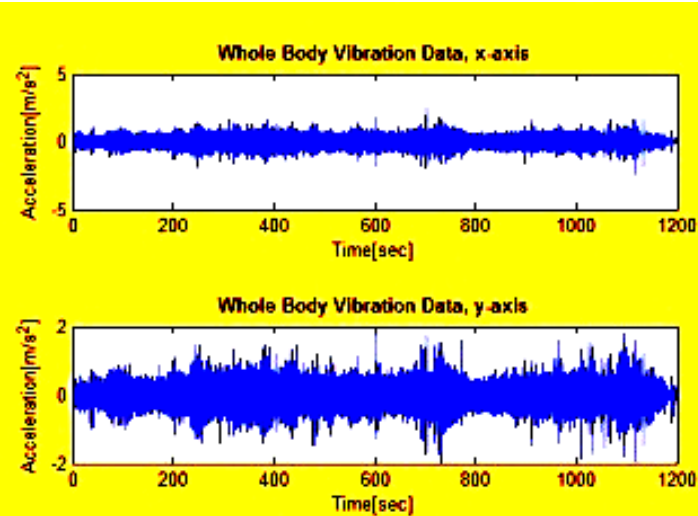

Whole Body VIbration Data, z-axis

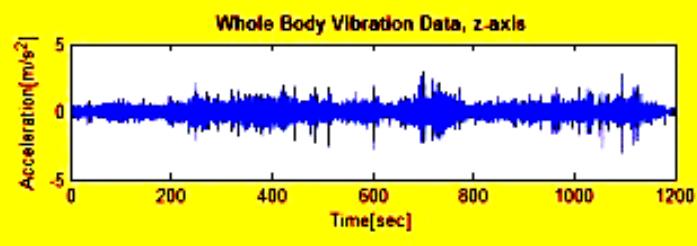

(b)

Figure 7. Vibration dose value calculation

Table 4. Whole-body vibration measurement data collected in the car

\begin{tabular}{|c|c|c|c|}
\hline Analysis Method & $\begin{array}{l}\text { Experiment } 1 \\
(5 \mathrm{~min}) \\
\text { Uneven and } \\
\text { curved road }\end{array}$ & $\begin{array}{c}\text { Experiment } 2 \\
(10 \text { min }) \\
\text { Even and curved } \\
\text { road }\end{array}$ & $\begin{array}{l}\text { Experiment } 3 \\
(10 \text { min }) \\
\text { Even and } \\
\text { straight road }\end{array}$ \\
\hline $\begin{array}{l}\text { Daily exposure to } \\
\text { vibration } A(8)\end{array}$ & $1.0782 \mathrm{~m} / \mathrm{s}^{2}$ & $0.8097 \mathrm{~m} / \mathrm{s}^{2}$ & $0.7928 \mathrm{~m} / \mathrm{s}^{2}$ \\
\hline $\begin{array}{l}\text { Exposure points } \\
\text { system }\end{array}$ & 464.96 points & 262.219 points & 251.381 points \\
\hline $\begin{array}{l}\text { Vibration dose } \\
\text { value (VDV) }\end{array}$ & $6.3314 \mathrm{~m} / \mathrm{s}^{1.75}$ & $4.3958 \mathrm{~m} / \mathrm{s}^{1.75}$ & $3.7264 \mathrm{~m} / \mathrm{s}^{1.75}$ \\
\hline $\begin{array}{l}\text { Daily exposure } \\
\text { action value time } \\
\left(0.5 \mathrm{~m} / \mathrm{s}^{2}\right)\end{array}$ & $53 \mathrm{~min}$ & 1 hour $33 \mathrm{~min}$ & 1 hour $37 \mathrm{~min}$ \\
\hline $\begin{array}{l}\text { Daily exposure } \\
\text { limit value time } \\
\left(1.15 \mathrm{~m} / \mathrm{s}^{2}\right)\end{array}$ & 4 hours $39 \mathrm{~min}$ & 8 hours $14 \mathrm{~min}$ & 8 hours $35 \mathrm{~min}$ \\
\hline Points per hour & 58.1201 points & 32.7773 points & 31.4226 points \\
\hline $\begin{array}{l}\text { Time to achieving } \\
1.75 \mathrm{~m} / \mathrm{s}^{1.75}\end{array}$ & 13 hours $32 \mathrm{~min}$ & 58 hours $14 \mathrm{~min}$ & 112 hours $45 \mathrm{~min}$ \\
\hline
\end{tabular}



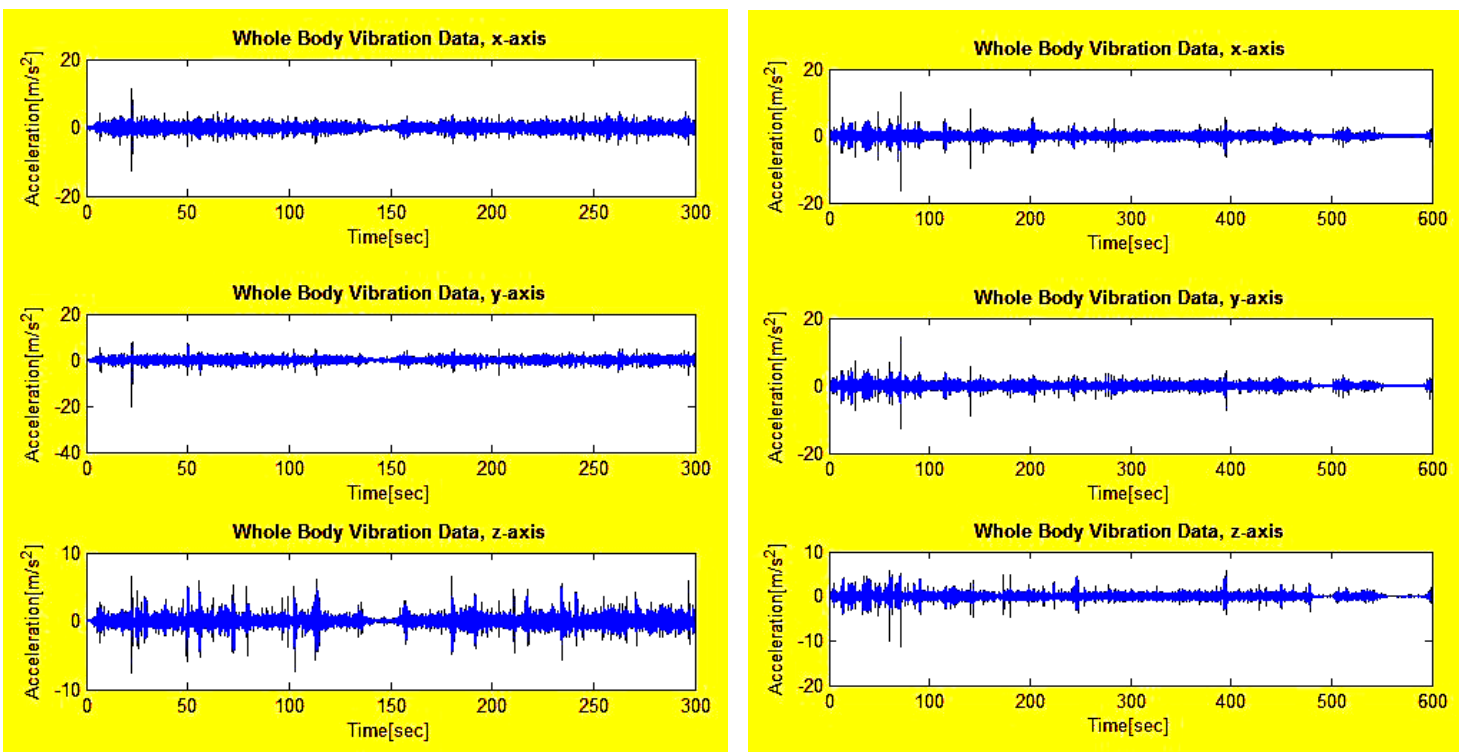

(a)

(b)
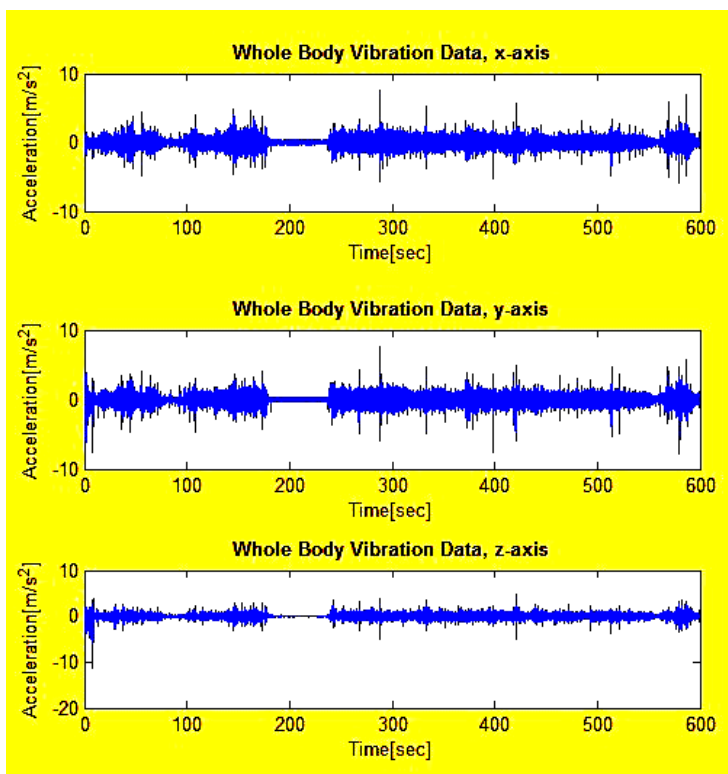

(c)

Figure 8 . Whole-body vibration measured using the custom data acquisition system (a) an uneven and curved road, (b) an even and curved road and (c) an even and straight road

The basic method (the frequency weighted root-mean-square (RMS) method) proposed in ISO 2631-1 is primarily applicable to the assessment of health risks from stationary vibrations not including severe multiple or single event shocks. Single event shocks can be analysed with the additional method running RMS in ISO 2631-1, although there is no information on health risk levels. The additional method VDV (frequency weighted fourth power vibration dose value) is more sensitive to shocks than the basic method, but it will still underestimate the health risks of vibration including severe shocks in comparison to the health risk of vibration not including severe shocks. 
The EU Physical Agents Directive uses the basic method for the assessment of health risk with VDV as an alternative. The two methods give different assessment results.

The RMS vibration magnitude is expressed in terms of the frequency weighted acceleration at the seat of a seated person or the feet of a standing person; it is expressed in units of metres per second squared $\left(\mathrm{m} / \mathrm{s}^{2}\right)$. The RMS vibration magnitude represents the average acceleration over a measurement period. It is the highest of three orthogonal axis values $\left(1.4 a_{\mathrm{wx}}, 1.4 a_{\mathrm{wy}}\right.$ or $\left.a_{\mathrm{wz}}\right)$ that are used for the exposure assessment. A frequency weighted acceleration value less than $0.45 \mathrm{~m} / \mathrm{s}^{2}$ shows that there are no negative health effects expected, whilst a frequency weighted value in between 0.45 $\mathrm{m} / \mathrm{s}^{2}$ and $0.90 \mathrm{~m} / \mathrm{s}^{2}$ suggests that negative health effects can be expected. However, a frequency weighted acceleration value greater than $0.90 \mathrm{~m} / \mathrm{s}^{2}$ suggests that a high risk of negative health outcomes is anticipated. The data from Table 5 indicate the RMS acceleration values for the exposure limit in 8 hours. Passengers exposed to whole-body vibration exposure must not exceed this standard value. Otherwise, passengers may experience health problems.

Table 5. Standard value of RMS acceleration

\begin{tabular}{|c|c|c|c|c|c|c|c|}
\hline Exposure Limit & 8 hrs & 4 hrs & $2.5 \mathrm{hrs}$ & $1 \mathrm{hr}$ & $30 \mathrm{~min}$ & $5 \mathrm{~min}$ & $1 \mathrm{~min}$ \\
\hline $\begin{array}{l}\text { RMS } \\
\text { acceleration }\end{array}$ & $\begin{array}{l}2.8 \\
\mathrm{~m} / \mathrm{s}^{2}\end{array}$ & $\begin{array}{l}4.0 \\
\mathrm{~m} / \mathrm{s}^{2}\end{array}$ & $\begin{array}{l}5.6 \\
\mathrm{~m} / \mathrm{s}^{2}\end{array}$ & $\begin{array}{l}11.2 \\
\mathrm{~m} / \mathrm{s}^{2}\end{array}$ & $\begin{array}{l}16.8 \\
\mathrm{~m} / \mathrm{s}^{2}\end{array}$ & $\begin{array}{l}27.4 \\
\mathrm{~m} / \mathrm{s}^{2}\end{array}$ & $\begin{array}{l}61.3 \\
\mathrm{~m} / \mathrm{s}^{2}\end{array}$ \\
\hline
\end{tabular}

The high magnitude of whole-body vibration exposure produced by trains and cars may contribute to musculoskeletal disorders in passengers. In reviewing the literature, a relationship was found between occupational vehicles and whole-body vibration exposure leading to musculoskeletal disorders. The term musculoskeletal disorder refers to conditions that involve the nerves, tendons, muscles and supporting structures of the body (Bernard, 1998). Exposure to WBV is another occupational risk factor that may cause LBP in operators of occupational vehicles (Bovenzi and Hulshof, 1999). In western countries, an estimated $4-7 \%$ of all employees are exposed to potentially harmful WBV. Experimental studies have found that the resonance frequencies of most of the organs and other parts of the body lie between 1 and $10 \mathrm{~Hz}$, which are in the range of frequencies found in occupational machines and vehicles. Six million workers are exposed to WBV, typically while in a seated position, including delivery vehicle drivers, forklift operators, helicopter pilots and construction equipment operators (Griffin, 2006). Tractor drivers have reported a 61-94\% prevalence of LBP and pathological changes in the spine, while heavy equipment drivers report a $70 \%$ prevalence of LBP. WBV is recognised as an important risk factor for occupational LBP in a variety of occupational groups (Joubert and London, 2007). At least four European countries have placed WBV injury on their scheduled lists of occupational diseases (Hulshof et al., 2002). Among such physical exposures encountered in the workplace, WBV has repeatedly been identified as a risk factor for LBP (Santos et al., 2008). Several epidemiologic studies conducted in the past several years have found strong evidence for a correlation between exposure to WBV and the occurrence of LBP (Noorloos et al., 2008). The NRCIM (2001) reported that there is evidence of a "clear relationship between back disorders and whole-body vibration". Joubert and London (2007) determined an association between back belt usage and back pain amongst forklift drivers exposed to WBV. LBP has been identified as one of the most costly disorders in the worldwide working population, and sitting has been associated 
with an increased risk of developing LBP (Lis et al., 2007). It has been showed that sustaining trunk sitting postures corresponding to mining vehicle operators generates back muscle fatigue and postural imbalance (Santos et al., 2008). On the other hand, Noorloos et al. (2008) have concluded that occupational participants exposed to WBV with a high BMI do not have an increased risk for the development of LBP, so the focus should be on other factors.

\section{CONCLUSION}

The WBV experienced by the human body increased when the magnitude of the vibration experienced by the passengers increased. This phenomenon can be shown by the increasing daily of exposure to vibration $A(8)$ value and the vibration dose value (VDV). Hence, it was clearly shown that most of the train and car passengers are exposed to WBV while travelling because the frequency-weighted acceleration values in the study were close to the value of the exposure limit according to ISO 2631-1:1997. Consequently, this exposure may cause health problems in passengers. Empirical studies have shown that there is a relationship between occupational vehicles and whole-body vibration that leads to musculoskeletal disorders. But, from the point of view of the Malaysian population, there has been insufficient research on this problem. Because of insufficient knowledge of diseases affected by WBV, passengers find it difficult to know of their exposure to WBV and the degree of exposure. In conclusion, more studies are needed to provide clear evidence of the association between WBV and musculoskeletal disorders, especially involving Malaysian occupational vehicles. Further studies with more focus on drivers of trains, cars and heavy vehicles are therefore suggested.

\section{ACKNOWLEDGEMENTS}

The authors wish to express their gratitude to University Kebangsaan Malaysia. The financial support by the Research University Grant UKM-GUP-BTT-07-25-169 is gratefully acknowledged.

\section{REFERENCES}

Bernard, B.P. 1997. Musculoskeletal disorders and workplace factors: a critical review of epidemiologic evidence for work-related musculoskeletal disorders of the neck, upper extremity, and low back. National Institute for Occupational Safety and Health, Cincinnati, $\mathrm{OH}$.

Bernard, B.P. 1998. Musculoskeletal disorders and workplace factors: a critical review of epidemiologic evidence for work-related disorders of the neck, upper extremities, and low back. NASA no. 19980001289.

Bovenzi, M. and Hulshof, C.T.J. 1999. An updated review of epidemiologic studies on the relationship between exposure to whole-body vibration and low back pain. International Archives of Occupational and Environmental Health, 72(6): 351365.

Burdorf, A. and Sorock, G. 1997. Positive and negative evidence of risk factors for back disorders. Scandinavian Journal of Work and Environmental Health, 23: 243256. 
Garg, A. and Moore, J.S. 1992. Epidemiology of low-back pain in industry. Occupational Medicine, 7: 593-608.

Grieco, A., Molteni, G., De Vito, G. and Sias, N. 1998. Epidemiology of musculoskeletal disorders due to biomechanical overload. Ergonomics, 41: 1253-1260.

Griffin, M.J. 1990. Handbook of human vibration. London: Academic Press.

Griffin, M.J. 2006. Health effects of vibration - the known and unknown. Conference on Human Vibration, Morgan Town, pp. 3-4.

Hagberg, M., Silverstein, B., Wells, R., Smith, M.J., Hendrick, H.W., Carayon, P. and Perusse, M. 1995. In: Kuorinka, I., Forcier, L. (Eds.), Work related musculoskeletal disorders (WMSDs): a reference book for prevention. London: Taylor \& Francis.

Hulshof, C., Van Der Laan, V.D., Braam, I. and Verbeek, J. 2002. The fate of Mrs. Robinson: criteria for recognition of whole-body vibration injury as an occupational disease. Journal of Sound and Vibration, 253, 185-194.

Kroemer, K., Kroemer, H.K. and Elbert, K.K. 2003. Ergonomics: how to design for ease and efficiency, $2^{\text {nd }}$ edition. City: Prentice Hall.

Lings, S. and Leboeuf-Yde, C. 2000. Whole-body vibration and low back pain: a systematic, critical review of the epidemiological literature 1992-1999. International Archives of Occupational and Environmental Health, 73: 290-297.

Lis, A.M., Black, K.M. Korn, H. and Nordin, M. 2007. Association between sitting and occupational LBP. European Spine Journal, 16: 283-298.

Matilla, M. 1996. Computer-aided ergonomics and safety - A challenge for integrated ergonomics. International Journal of Industrial Ergonomics, 17: 309-314.

National Research Council, Institute of Medicine, 2001. Musculoskeletal disorders and the workplace: low back and upper extremities. Washington, D.C.: National Academy Press.

Noorloos, D., Tersteeg, L., Tiemessen, I.J.H., Hulshof, C.T.J. and Frings-Dresen, M.H.W. 2008. Does body mass index increase the risk of low back pain in a population exposed to whole body vibration? Applied Ergonomics, 39: 779-785.

Palmer, K.T., Griffin, M.J. and Bendall, H. 2000. Prevalence and pattern of occupational exposure to whole body vibration in Great Britain: findings from a national survey. Occupational Environmental Medicine, 57: 229-236.

Santos, B.R., Larivière, C., Delisle, A., Plamondon, A., Boileau, P.E. and Imbeau, D. 2008. A laboratory study to quantify the biomechanical responses to whole-body vibration: The influence on balance, reflex response, muscular activity and fatigue. International Journal of Industrial Ergonomics, 38: 626-639.

van der Windt, D.A., Thomas, E., Pope, D.P., de Winter, A.F., Macfarlane, G.J., Bouter, L.M. and Silman, A.J. 2000. Occupational risk factors for shoulder pain: a systematic review. Occupational and Environmental Medicine, 57: 433-442.

Van Tulder, M.W., Koes, B.W. and Bouter, L.M. 1995. A cost-of-illness study of back pain in The Netherlands. Pain, 62: 233-240.

Waddell, G. and Burton, A.K. 2001. Occupational health guidelines for the management of low back pain at work; evidence review. Occupational Medicine, 51: 124135.

Wang, M.J.J., Chung, H.C. and Wu, H.C. 2003. The evaluation of manual FOUP handling in $300 \mathrm{~mm}$ wafer fab. IEEE Transactions on Semiconductor Manufacturing, 16: 551-554. 
Weestgard, R.H. and Winkel, J. 1997. Ergonomic intervention research for improved musculoskeletal health: a critical review. International Journal of Industrial Ergonomics, 20: 463-500.

\section{Nomenclature}

$\begin{array}{ll}\mathrm{Hz} & \text { Hertz } \\ \mathrm{kHz} & \text { kiloHertz }\left(10^{3}\right) \\ \mathrm{km} / \mathrm{h} & \text { kilometre per hour } \\ \mathrm{m} & \text { metre }\left(10^{2}\right) \\ \mathrm{mA} & \text { milliAmpere }\left(10^{-3}\right) \\ \mathrm{min} & \text { minute } \\ \mathrm{s} & \text { second } \\ \mathrm{V} & \text { voltage }\end{array}$

